\title{
Effects of inhaled ceramic fibres on macrophage function of rat lungs
}

Yasuo Morimoto, Hiroshi Yamato, Masamitsu Kido, Isamu Tanaka, Toshiaki Higashi, Akihiro Fujino, Yasuyuki Yokosaki

\begin{abstract}
To evaluate the biological effect of ceramic fibres on the clearance function of alveolar macrophages (AMs) morphological changes and phagocytic activity of AMs were assessed. Rats were exposed to respirable ceramic fibres with a mass median aerodynamic diameter of $4.4 \mu \mathrm{m}$ and a concentration of $20.1 \mathrm{mg} / \mathrm{m}^{3}$ in an exposure chamber. They were killed after one week (group $A$ ) and two weeks (group B) of exposure, and four weeks (group C) and 12 weeks (group D) after exposure for two weeks. The AMs recovered by bronchoalveolar lavage (BAL) from each test group were incubated with yeast and phagocytic activity was determined by counting the number of yeast cells in AMs. Morphological features of AMs were assessed by scanning electron microscopy and quantified according to morphological changes. Total cell counts in BAL fluid from exposed rats in group $A$ were higher than in control rats. Phagocytic activity of exposed AMs in group $B$ and $C$ exceeded that of control AMs. Morphological changes of the exposed $A M$ s in groups $A$, $B$, and $C$ were greater than those of control AMs. These findings suggest that ceramic fibres induced the phagocytic activity and morphological changes in AMs, and that the clearance function of AMs was stimulated by the inhaled ceramic fibres.
\end{abstract}

(Occup Environ Med 1994;51:62-67) Respiratory Disease Y Yokosaki M Kido

Department of Environmental Health Engineering H Yamato

I Tanaka

Department of Health Policy and

Management

University of

Occupational and

Environmental

Health, Japan

A Fujino

T Higashi

Requests for reprints to: Yasuo Morimoto MD, Division of Respirator Disease, University of Occupational and Environmental Health, 1-1, Iseigaoka, Yahatanishiku, Kitakyushu 807, Japan.

Accepted 22 February 1993

Occupational and environmental exposure to inhaled asbestos dust is thought to produce both pulmonary fibrosis and neoplasia. ${ }^{12}$ Recently, various types of man made mineral fibres have been developed as substitutes for asbestos; the demand for such products is increasing. ${ }^{3}$ Ceramic fibres, one type of man made mineral fibres, are also used widely as high temperature insulation and for stuffing expansion joints. Such fibres are thought to possess the same adverse biological effects as asbestos because of their similar physiochemical properties. ${ }^{3}$ Kilburn et al reported that fibre glass seemed to produce human disease that was similar to asbestosis. ${ }^{4}$ There are, however, no epidemiological studies involving ceramic fibres, and the results of animal studies on the adverse effects of ceramic fibres are conflicting. Davis et al reported that bronchial carcinoma or fibrosis occurred in rats that inhaled ceramic fibres, ${ }^{5}$ whereas Smith et al did not find lung disease in rats and hamsters exposed to such fibres. ${ }^{67}$ Thus it is not clear whether ceramic fibres have adverse effects on the lung.

Alveolar macrophages (AMs) play an important part in maintaining the sterility of the lung by phagocytosis and hence removal of the inhaled particles. ${ }^{8}$ Because the deposition of mineral fibres in the lung is involved in producing pulmonary fibrosis and neoplasms, ${ }^{9}$ we have studied the clearance of mineral fibres by AMs. Investigation of macrophage morphology and phagocytosis is essential to understand the mechanisms of clearance of inhaled particles.

To evaluate the effects of ceramic fibres on the clearance function of AMs, we conducted an inhalation exposure study of ceramic fibres in rats and evaluated the morphological and phagocytic changes in AMs after periods of exposure and recovery.

\section{Materials and methods \\ ANIMALS}

Male Wistar rats (nine weeks old) were studied. They were kept in a chamber and observed for four to five days before the experiment.

FIBRES

The ceramic fibres (alumina silicate refractory fibres) used in the present study were made by Nippon Steel Chemical Co (Kitakyushu, Japan). Bulk ceramic fibres were disintegrated three times with an ultracentrifugal mill (Retch Co, Germany) to obtain particles for exposure.

\section{EXPOSURE SYSTEM}

Figure 1 is a diagram of the experimental apparatus developed by Tanaka and Akiyama. ${ }^{10}$ This system maintained a constant concentration of mineral fibres during exposure.

\section{CONCENTRATION AND SIZE DISTRIBUTION IN} THE EXPOSURE CHAMBER

The concentration of ceramic fibres was measured gravimetrically at daily intervals by the isokinetic suction of air through a glass filter. The size distribution of the aerosol in the exposure chamber was found with a cascade impactor (air sampler, Andersen type, model AN-200, Shibata Scientific Technology Ltd, Japan). The mass median aerodynamic diam- 
Figure 1 Schematic diagram of dust exposure system.

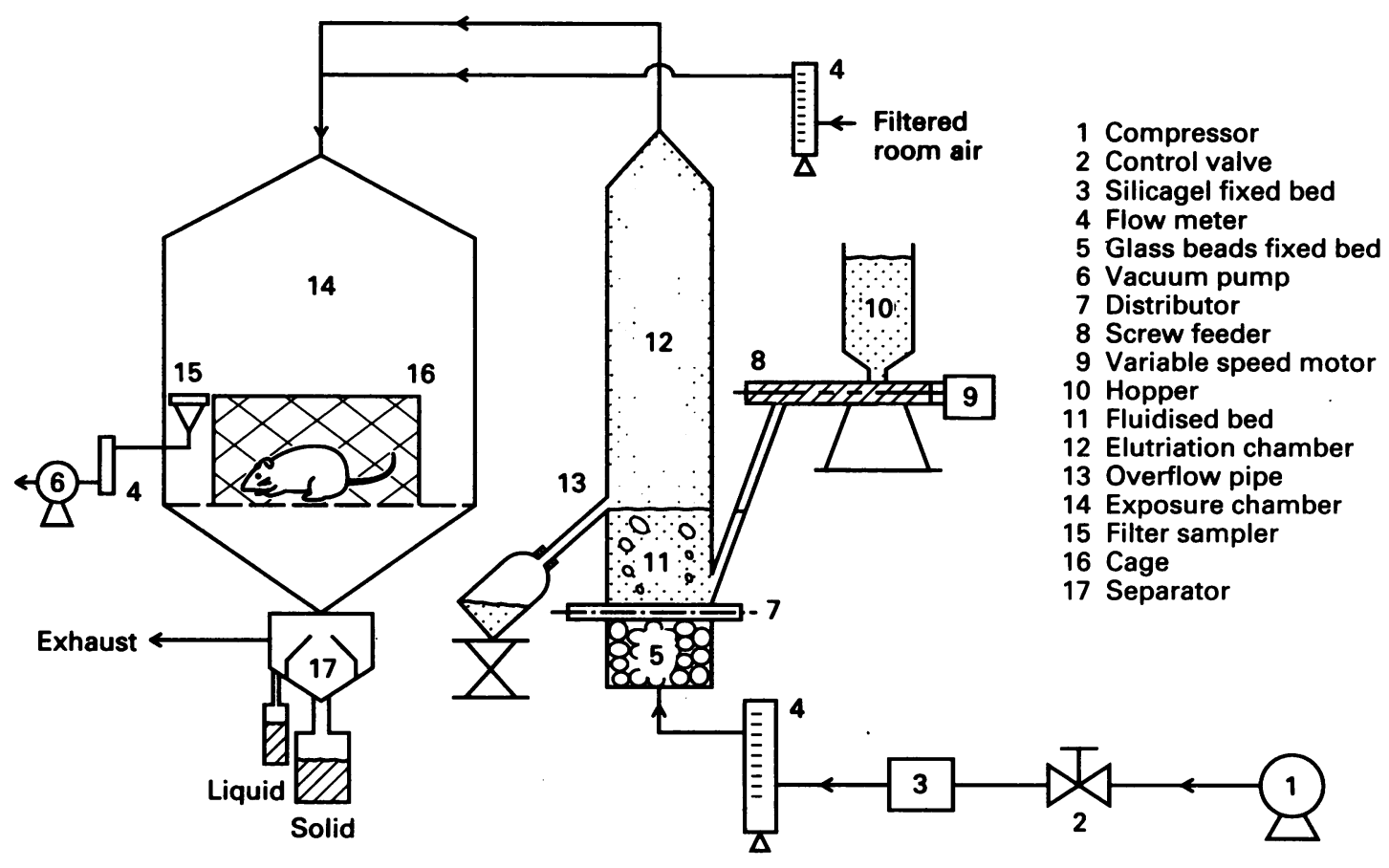

eter of the ceramic fibres was $4.4 \mu \mathrm{m}$ and the geometric $\mathrm{SD}$ was $2 \cdot 0$. As the sampler is not suited to obtaining fibrous materials, it was used in this study only to verify that the test sample was respirable.

\section{EXPERIMENTAL DESIGN}

Figure 2 shows the experimental protocol. Rats were exposed to dust clouds of $20 \cdot 1$ $\mathrm{mg} / \mathrm{m}^{3}$ in the inhalation chamber for six hours daily five days a week for a maximum of two weeks. Groups A and B were removed from the chamber and killed for study after one and two weeks exposure. Groups C and D were removed after exposure for two weeks and killed after recovery of four and 12 weeks. Rats were divided into exposed ( $n=$ $5)$ and control $(n=5)$ groups in each exposure and clearance condition.

\section{BRONCHOALVEOLAR LAVAGE}

Each animal was anaesthetised by an intraperitoneal injection of phenobarbital and killed by exsanguination. The trachea was then cannulated, and the lungs were lavaged with a total of $50 \mathrm{ml}$ of saline in 6 to $8 \mathrm{ml}$ aliquots. The bronchoalveolar lavage (BAL) fluid recovered was then centrifuged $(\times 1200$ $\mathrm{g}$ for 10 minutes), and the supernatants were removed. The cell pellet was resuspended in

Figure 2 Experimental protocol.

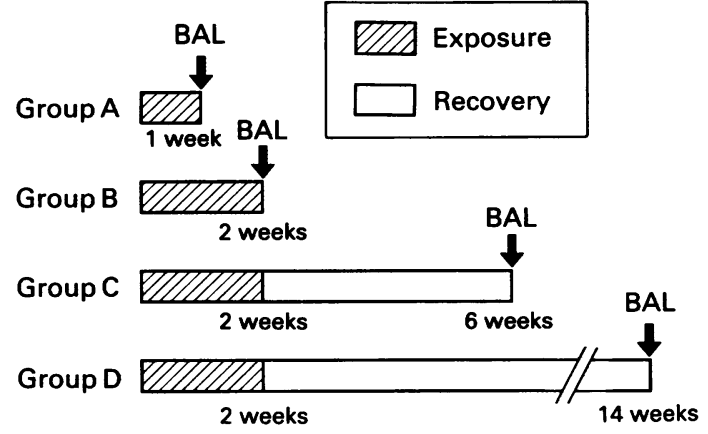

RPMI 1640 medium (Whittak Bioproducts, Walkersville, Maryland, USA) and supplemented with $5 \%$ inactivated fetal bovine serum (GIBCO Laboratories, Grand Island, NY, USA). Cells were counted in a haemacytometer chamber and their viability was determined by trypan blue exclusion. Differential cell counts were made with Wright-Giemsa staining.

PREPARATION OF MONOLAYERS FOR SCANNING ELECTRON MICROSCOPY

After an additional wash, a suspension of AMs containing $1 \times 10^{5}$ cells was plated on a small glass slide placed inside a culture dish. The cells were incubated for 60 minutes in a $\mathrm{CO}_{2}$ incubator $\left(5 \% \mathrm{CO}_{2}, 95 \%\right.$ humidified room air) at $37^{\circ} \mathrm{C}$. The monolayers were then rinsed vigorously in phosphate buffered saline (PBS) solution to remove non-adherent cells. Next, cells were fixed overnight at room temperature with glutaraldehyde in HEPES solution. After fixing, coverslips were rinsed in a PBS solution and dehydrated through a series of graded acetone steps. Samples were critical point dried with $\mathrm{CO}_{2}$ as the fluid. The specimens were sputter coated with platinum and morphological characteristics of AMs were studied in a scanning electron microscope (S700 , Hitachi Japan) to evaluate the activation of their clearance function. ${ }^{11}$ Cells were classified by shape according to Finch et al. ${ }^{12}$ Three classifications were used to characterise an AM-namely, rounded, spread, and intermediate (fig 3, table 1). Each shape of AMs was scored as in fig 3 (rounded $=0$, intermediate $=1$, spread $=2$ ). The scanning electron microscope score was the ratio of total score counts from 50 exposed AMs to

PHAGOCYTIC CAPACITY OF ALVEOLAR MACROPHAGES

To prepare whole heat inactivated cells, yeast particles were sterilised in an oven at $105^{\circ} \mathrm{C}$ that of control AMs. 
Table 1 Morphological classification of pulmonary alveolar macrophages by scanning electron microscopy

\begin{tabular}{lll}
\hline Term & Definition & Score \\
\hline Rounded cell & $\begin{array}{l}\text { Highly rounded central area with } \\
\text { little or no membrane spread along } \\
\text { the coverslip }\end{array}$ & 0 \\
Intermediate & $\begin{array}{l}\text { Highly rounded central area with } \\
\text { A }\end{array}$ & $\begin{array}{l}\text { membrane spread along the coverslip } \\
\text { Indistinct gradual rounding of the } \\
\text { central area without much membrane } \\
\text { spread along the coverslip }\end{array}$ \\
B & $\begin{array}{l}\text { No distinct rounding of the } \\
\text { central area } \\
\text { Spread thinly over the coverslip }\end{array}$ & 2 \\
\hline
\end{tabular}

for one hour. Alveolar macrophages at a concentration of $1 \times 10^{5} / \mathrm{ml}$ were incubated with $2 \times 10^{6} / \mathrm{ml}$ yeast particles for 30 minutes at $37^{\circ} \mathrm{C}$ in humidified air with $5 \% \mathrm{CO}_{2}$. Cells were held over wet ice at $4^{\circ} \mathrm{C}$ in a centrifuge tube to keep them metabolically inactive, and stained with a phenol fuchsin stain. To evalu-

Figure 3 Morphological classification of pulmonary alveolar macrophages by scanning electron microscopy. $(A)$ rounded cell, $(B)$ intermediate cell $A$, $(C)$ intermediate cell $B$, (D) spread cell.
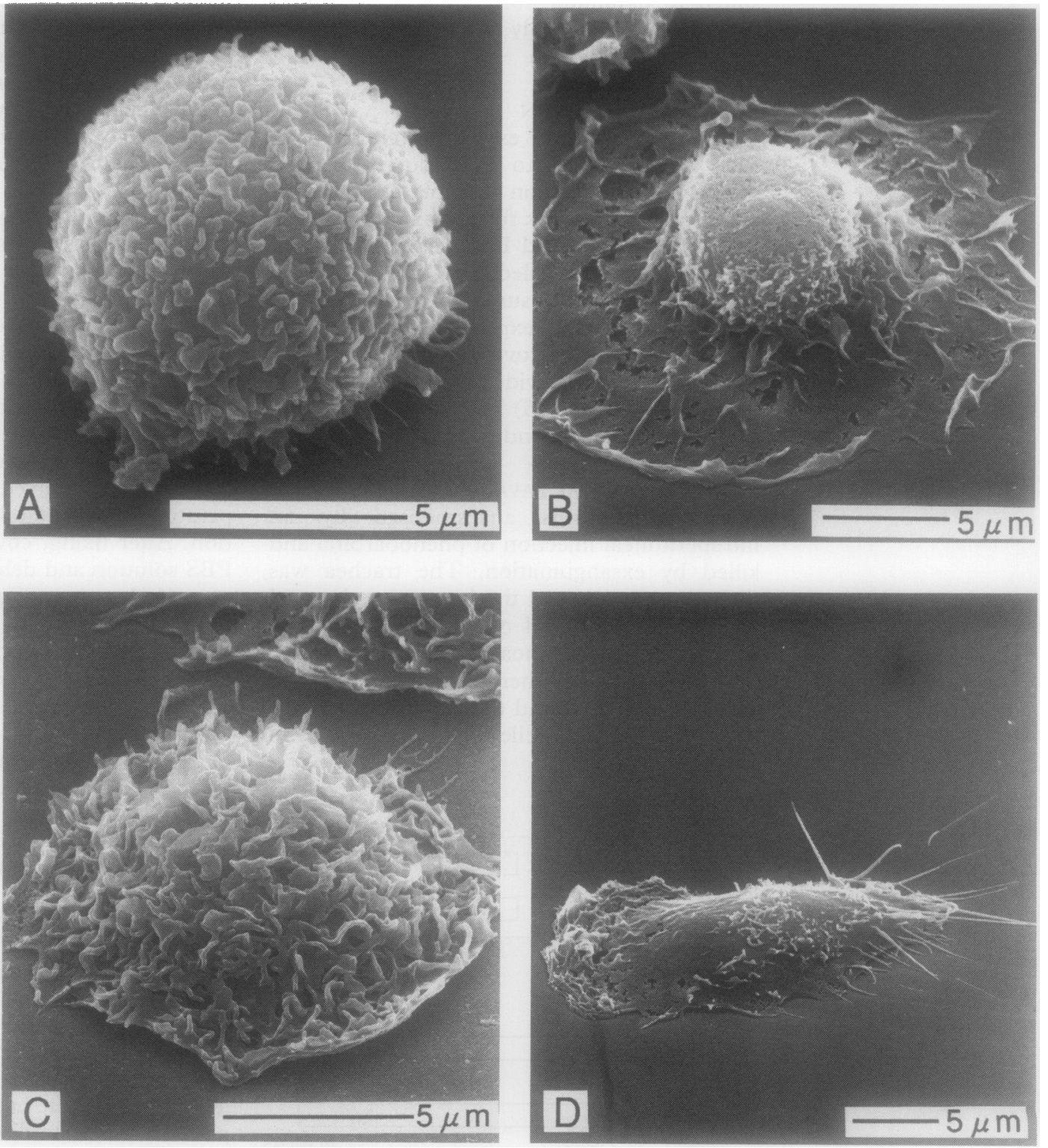

ate the phagocytosis of the yeast cells, the number of internalised yeast cells was counted in individual AMs with light microscopy. Phagocytosis was reported as the ratio of the number of phagocytosed yeasts in 100 exposed AMs to that in control AMs.

STATISTICAL ANALYSIS

Values were expressed as the mean (SEM). The difference between values was examined by the Mann-Whitney $U$ test.

\section{Results}

TOTAL AND DIFFERENTIAL CELL COUNTS IN BAL FLUID

Total cell count in the exposed rats was significantly increased at group A. Differences between the exposed and control rats in groups B, C, and D, were not statistically significant. There were no significant differences in the differential cell counts of the exposed $v$ control rats at any time. The AMs predominated in both groups (fig 4, table 2). 
Figure 4 Comparison of total cell count and differential cell counts in bronchoalveolar lavage (BAL) fluid between different periods of exposure and clearance. Group $A$, one week exposure; group $B$, two weeks exposure; group $C$ four weeks recovery time after two weeks exposure, group $D, 12$ weeks recovery time after two weeks exposure.

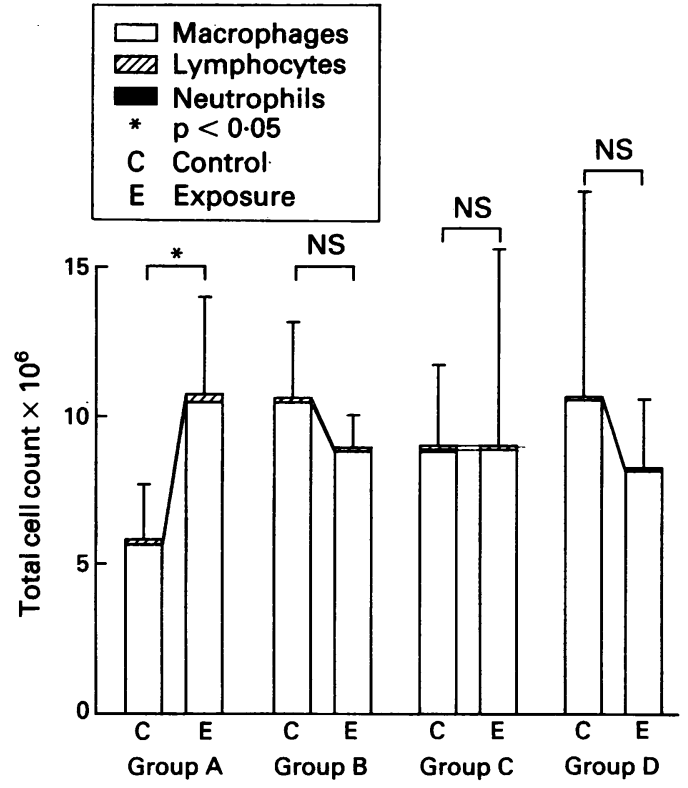

PHAGOCYTOSIS OF ALVEOLAR MACROPHAGES The phagocytic activity of AMs from the exposed rats significantly exceeded that of the control rats in groups B and C. The phagocytic capacity of exposed AMs in group D was not activated. (fig 5)

\section{MORPHOLOGICAL FEATURES OF ALVEOLAR MACROPHAGES}

The scanning electron microscope score of the exposed AMs in groups A, B, and C was significantly higher than that of controls. The AMs from exposed rats, especially group $B$, were accompanied by a greater proportion of spreading cells. The exposed AMs, however, tended to become round in group $D$. There was no significant difference in scanning electron miscroscope score between the exposed and the control AMs in group D (fig 6).

\section{Discussion}

We studied the effect of inhaled ceramic fibres on the clearance function of AMs under four different exposure periods and recovery times. Of the functions of the AM, phagocytosis is deeply involved in clearance of mineral fibres. ${ }^{8}$

Once inside the phagocyte, the particle may remain static until events result in migration of the cell toward an exit from the lung. Subsequently, the AMs enter the bronchial surface to leave the lung through the tracheobronchial mucociliary escalator. ${ }^{8}$ Figure 7

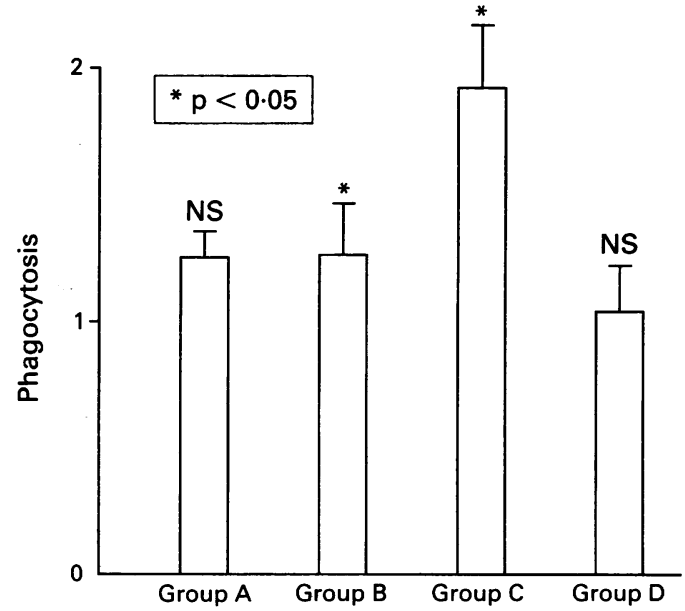

Figure 5 Comparison of phagocytosis of pulmonary alveolar macrophages (AMs) between different periods of exposure and clearance. Phagocytic index is the ratio of phagocytosis by exposed AMs to phagocytosis by control AMs. Groups as in fig 4.

shows that the AMs that tried to phagocytise the fibres were transfixed by the ceramic fibre. It is difficult for AMs to transfer ceramic fibres longer than their own diameter. Yamato et al reported that geometric median length and geometric mean diameter of inhaled ceramic fibres in rat lungs were 5.4-6.0 $\mu \mathrm{m}$ and $0.56-0.88 \mu \mathrm{m} .{ }^{13}$ The mean number of inhaled fibres was 3.3-5.6 $\times 10^{6}$ in the rat lung and about $80 \%$ of ceramic fibres were shorter than $10 \mu \mathrm{m}$. Therefore, it was thought that AMs contribute to the clearance of shorter ceramic fibres, which they are able to phagocytose.

It was reported that solubility of ceramic fibres contributed to the clearance of the inhaled fibres ${ }^{13}$; Bernstein et al indicated that the solubility rate of fibres within AMs was almost twice that of the free fibres in tissue. ${ }^{14}$ Long fibres that were partially engulfed by AMs had dissolved more extensively than those that lay free. ${ }^{15}$ Phagocytosis seems to contribute to the solubility of mineral fibres. Disolution of mineral fibres by the AMs may be related to their proteolytic enzymes and low $\mathrm{pH}$.

We evaluated the phagocytosis of yeast particles by AMs in this study. Warheit and Hartsky indicated that chrysotile asbestos depressed the phagocytic capacity of AMs. ${ }^{16}$ We found, however, that the AMs exposed to ceramic fibres had an increased phagocytic activity at two weeks of exposure and at four weeks of recovery time. Therefore, the activa-

Table 2 Mean total cell count, phagocytosis, and scanning electron microscope score between control (C) and exposed (E) groups

\begin{tabular}{lcccc}
\hline & Group A & Group B & Group C & Group D \\
\hline Total cell count $\left(10^{6} / \mathrm{ml}\right):$ & $5 \cdot 8(1 \cdot 9)$ & $10 \cdot 7(2 \cdot 5)$ & $9 \cdot 1(2 \cdot 7)$ & $10 \cdot 4(7 \cdot 7)$ \\
C & $10 \cdot 7(3 \cdot 2)^{\star}$ & $9 \cdot 0(1 \cdot 1)$ & $9 \cdot 1(6 \cdot 6)$ & $8 \cdot 4(2 \cdot 3)$ \\
E & $1 \cdot 25(0 \cdot 1)$ & $1 \cdot 29(0 \cdot 18)^{\star}$ & $2 \cdot 25(0 \cdot 28)^{\star}$ & $1 \cdot 02(0 \cdot 21)$ \\
Phagocytosis & $1 \cdot 53(0 \cdot 29)^{\star}$ & $1 \cdot 60(0 \cdot 07)^{\star \star}$ & $1 \cdot 34(0 \cdot 13)^{\star \star}$ & $1 \cdot 19(0 \cdot 29)$ \\
\hline
\end{tabular}

${ }^{\star} \mathrm{p}<0.05 \mathrm{E} v \mathrm{C} ;{ }^{\star \star} \mathrm{p}<0.01 \mathrm{E} v \mathrm{C}$ 
Figure 6 Comparison of scanning electron microscope (SEM) score of pulmonary alveolar macrophages ( $A M$ s) between different periods of exposure and clearance. Scanning electron microscope score was the ratio of the total score of exposed AMs to total score of control AMs. Groups as in fig 4.

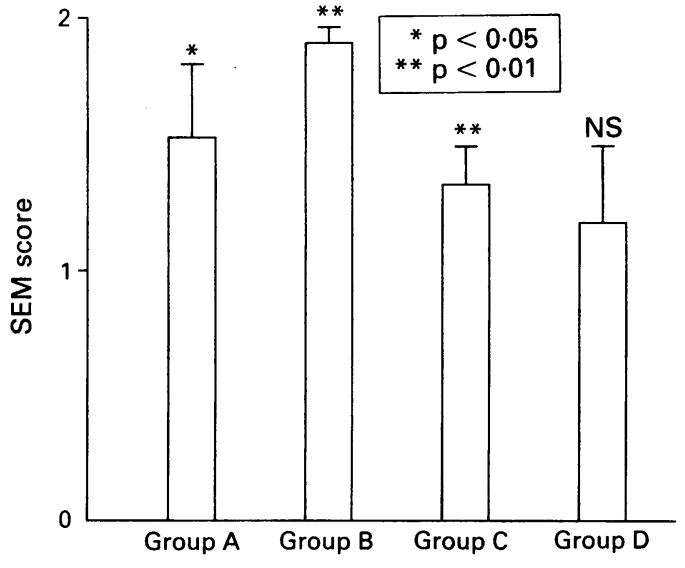

tion of phagocytosis of AMs was suggested to enhance the clearance of ceramic fibres. The difference in the response of AMs to chrysotile asbestos and ceramic fibres may be related to differences in the cytotoxicity of these fibres. Chrysotile is highly cytotoxic and would thus damage the cells more than would the ceramic fibres. ${ }^{17}$

Use of the scanning electron microscope to

Figure 7 Scanning electron micrograph showing pulmonary alveolar macrophages that have phagocytosed ceramic fibres.
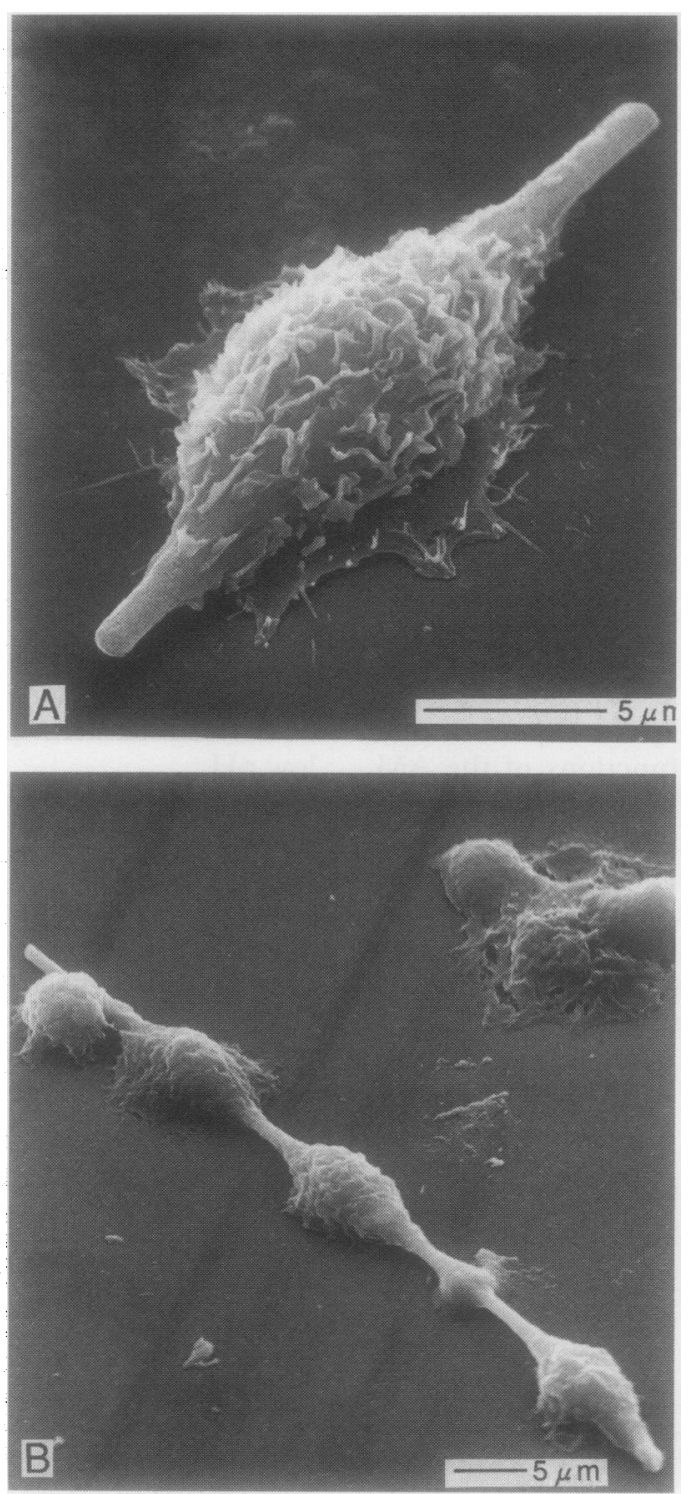

evaluate AM shape, showed morphological changes. The surface of AMs exposed to ceramic fibres showed a plate like appearance compared with the unexposed AMs after exposure for one and two weeks, and after recovery for four weeks.

Donaldson et al reported that, on light microscopical examination, AMs exposed to chrysotile showed more spreading activity during exposure periods and recovery time. ${ }^{18}$ Our findings are in agreement. Figure 7 shows that AMs spread to cover the ceramic fibres. Parakkal et al have reported that filopodia attached to the particle subsequently became confluent to form a continuous membrane that enveloped the particle and eventually engulfed it. ${ }^{19}$ Therefore, a morphological change-for example by a thin membrane-may contribute to clearance of ceramic fibres, especially those shorter than the diameter of AMs.

The changes in phagocytosis and morphology of the AMs exposed to ceramic fibres did not significantly exceed those of control AMs after a period of 12 weeks of recovery after exposure. This shows that the clearance function of AMs did not change continuously through the periods of exposure and recovery. It was reported that chrysotile or silica, which are known to cause fibrosis, changed the spreading of AMs during both the exposure and recovery periods. ${ }^{18}$ The low response of AMs to ceramic fibres suggests that ceramic fibres possess a lower cytotoxicity than chrysotile or silica.

In summary, we evaluated the clearance function of AMs to inhaled ceramic fibres in rats. These fibres induced phagocytic activity and morphological changes in the alveolar macrophages. Whereas it was suggested that the clearance function of AMs was stimulated by the inhaled ceramic fibres, this function was not continuously changed throughout the periods of exposure and recovery. Further investigation with this method is required to evaluate the effects of long term exposure.

1 Becklake MR. Asbestos-related diseases of the lung and other organs: their epidemiology and implications fo clinical practice. Am Rev Respir Dis 1976;114:187-227.

2 Selikoff IJ. Lee DHK. Asbestos and disease. New York: Academic Press, 1978; 3-32.

3 World Health Organization. Man-made mineral fibres. Geneva: UNEP, ILO, and WHO, 1988. (Environmental health criteria, 77;11-32.)

4 Kilburn KH, Powers D, Warshaw RH. Pulmonary effects of exposure to fine fibreglass: irregular opacities and small airways obstruction. $\mathrm{Br} \mathcal{F}$ Ind Med 1992;49. 714-20.

5 Davis JMG, Addison J, Bolton RE, Donaldson K, Jones $A D$, Wright $A$. The pathogenic effects of fibrous ceramic aluminium silicate glass administered to rats by inhalation or peritoneal injection. In: WHO/LARC Conference Biological effects of man-made mineral fibres. Copenhagen: World Health Organization, Regional

Smith DM, Ortiz LW, Archuleta RF. Long-term exposure of Syrian hamsters and Osborne-Mendel rats to aerosolized $0.45 \mu \mathrm{m}$ mean diameter fibrous glass. In WHO/LARC Conference. Biological effects of man-made mineral fibres. Copenhagen: World Health Organization Regional Office for Europe. 1984;2.253-72.

7 Smith DM, Ortiz LW, Archuleta RF, Johnson NF. Long term health effects in hamsters and rats exposed chronically to man-made vitreous fibres. Ann Occup Hyg 1987;31:731-54.

8 Green GM. Alveolobronchiolar transport mechanisms. Arch Intern Med 1973;131:109-14.

9 Friedrichs $\mathrm{KH}$, Otto $\mathrm{H}$. Fibers in human lung dust samples: a scanning electron microscope study. Am Ind Hyg
Assoc $\mathcal{F} 1981 ; 42: 150-6$. 
10 Tanaka I, Akiyama T. A new dust generator for inhalation toxicity studies. Ann Occup Hyg 1984;28:157-62.

11 Warheit DB, Hill LH, Brody AR. Pulmonary macrophage phagocytosis: quantification by secondary and backscattered electron imaging. Scanning Electron Microscopy 1983;6:431-7.

12 Finch GL, Fisher GL, Hayes TL, Golde DW. Morphological studies of cultured human pulmonary macrophages. Scanning Electron Microscopy 1980;3:315-26.

13 Yamato $H$, Tanaka I, Higashi T, Kido M. Determinan factor for clearance of ceramic fibres from rat lungs. $\mathrm{Br}$ f Ind Med 1992;49:182-5.

14 Bernstein DM, Drew RT, Schidlovsky G, Kuschner M. Pathogenicity of MMMF and the contrasts with natural fibres In: WHOILARC Confere fibres. In: Wriollare Conference. Biological effects of man-made mineral fibres. Copenhagen: World Health Organization, Regional Offce for Europe. 1984;2:

15 Morgan A, Holmes A, Davison W. Clearance of sized glass fibres from the rat lung and their solubility in vivo. Ann Occup Hyg 1982;25:317-31.

16 Warheit DB, Hartsky MA. Assessments of pulmonary macrophage clearance responses to inhaled particulates. Scanning Microsc 1988;2:1069-78.

17 Richards RJ, Jacoby F. Light microscope studies on the effects of chrysotile asbestos and fiber glass on the morphology and reticulin formation of cultured lung fibroblasts. Environ Res 1976;11:112-21.

18 Donaldson $K$, Bolton RE, Jones A, Brown GM, Robertson MD, Slight J, et al. Kinetics of the bronchoalveolar leucocyte response in rats during exposure to equal airborne mass concentrations of quartz, chrysotile asbestos, or titanium dioxide. Thorax 1988; 43:525-33.

19 Parakkal P, Pinto J, Hanifin JM. Surface morphology of human mononuclear phagocytes during maturation and human mononuclear phagocytes during maturation and
phagocytosis. Fournal of Ultrastructure Research 1974; 48:216-26. 